\title{
Ethics and legalities associated with independent medical evaluations
}

\author{
Shanil Ebrahim PhD MSc, Helen Sava BA LLB, Regina Kunz MD MSc, Jason W. Busse DC PhD
}

Competing interests: Jason Busse acts as a consultant to Prisma Health Canada, a private incorporated company funded by employers and insurers, which consults on and manages long-term disability claims. Helen Sava is a principal lawyer at Sava Associates and works with private disability insurers. Regina Kunz is the Director of the Swiss

Academy of Insurance Medicine at the University Hospital Basel. The academy is funded in part by donations from public insurance companies and a consortium of private insurance companies. No other competing interests were declared.

This article has been peer reviewed.

Correspondence to: Shanil Ebrahim, shanil.ebrahim @mcmaster.ca

CMAJ 2014. DOI:10.1503 /cmaj.131509
1 $\mathrm{n}$ independent medical evaluation (IME) is an assessment performed by a physician who does not treat the patient. Disability insurers, employers or lawyers often request an IME when faced with uncertainty about the cause or nature of a claimed disability, or the functional status and/or rehabilitation potential of the claimant. Independent medical evaluators are retained by the requesting party; therefore, their relationship with the patient is different from the relationship in the traditional physician-patient model. Because the primary responsibility of the independent medical evaluator is to provide a service for the hiring third party and not for the patient, legal and ethical concerns may arise during an IME that would not typically arise within the context of a standard physicianpatient relationship. Particularly challenging and controversial issues are duty of care within the evaluator-examinee relationship, disclosure of important medical findings, and the right of the examinee to access the IME report, which could include working notes.

In a standard physician-patient relationship, a physician is legally obligated to act in the best interests of his or her patient, ${ }^{1}$ and failure to do so could leave a physician liable for damages. ${ }^{2}$ Some argue that because the independent medical evaluator is hired by a third party, the evaluator owes no legal duty of care to the examinee and has no liability for any resultant harm. ${ }^{3}$ The counter-argument is that physicians always owe a duty of reasonable care. In fact, some courts have suggested that an IME creates a limited duty to "avoid harming the patient." ${ }_{4,5}$ Unfortunately, legal rulings offer no clarity as to what constitutes unreasonable harmful behaviour. Explicitness and transparency in communication about the nature of the assessment, about how certain aspects may be uncomfortable but will not cause harm (e.g., strength testing involving sore muscles), about why such testing is important for informing the IME, as well as genuine respect and consideration for the examinee, should reduce the likelihood of claims of harm to arise.

What happens if the independent medical evaluator discovers a medical problem that requires treatment? Is the evaluator obligated to disclose this information to the examinee? Again, disparate viewpoints exist. Some suggest that evaluators should not disclose medical information that is unrelated to the IME and consider it inappropriate "meddling." ${ }^{\circ}$ However, has the evaluator failed in his or her duty to avoid harm if withholding information has caused the examinee to be harmed in any way - even years after the IME? Some Canadian courts have suggested that evaluators should take reasonable steps to ensure that the examinee is advised of all important medical findings that affect, or may affect, his or her health.

A 2001 ruling $^{7}$ provides illustration: in 1973, a patient underwent a splenectomy that left him at increased risk of serious pneumococcal infections. In the $1980 \mathrm{~s}$, a pneumococcal vaccine became available for reducing this risk. In 1995 , the patient applied for insurance benefits and his family doctor referred him for an IME. During the examination, the independent medical evaluator became aware that the examinee had not received the vaccine, and hence was not receiving optimal management. Failure to disclose information left the examinee vulnerable and he contracted pneumococcal meningitis two years later. A court determined that because the treating team of the examinee retained the evaluator, a duty was owed to the examinee to advise him of anything

All editorial matter in CMAJ represents the opinions of the authors and not necessarily those of the Canadian Medical Association. 
of importance to his health, including the existence of the vaccine. It is likely that a court could find that the duty extends to situations in which the evaluator is retained by a third party other than the treatment team of the examinee.

The Canadian Medical Protective Association (CMPA) provides its physician members with medicolegal advice, risk-management education and legal assistance related to clinical practice. The association has advised that although independent medical evaluators are not retained to provide treatment, it is generally prudent for them to inform the examinee about important health information discovered during an examination, even if it is unrelated to the reason for the IME. ${ }^{8}$

Who has the right to have access to the results of an IME - the examinee, the employer or the third party paying for the IME? Following an IME, evaluators generally release detailed medical information and findings to the referral source, unless the referral source is the employer. ${ }^{1}$ Employers, with the possible exception of those who manage disability internally with appropriate safeguards to ensure confidentiality, are not entitled to the medical information of their employees and are to receive only information on restrictions and limitations that directly affect workplace accommodation. ${ }^{9}$

Although some independent medical evaluators have advocated for all parties involved to receive a copy of the report, ${ }^{10}$ others have argued that the hiring third party can withhold the report from the examinee and his or her treatment team..$^{6,11,12}$ Whether a case is in litigation may have some bearing on this issue, because the rules of court in each province or territory can affect disclosure obligations by a third party who requests an IME. According to the Personal Information Protection and Electronic Documents Act, an examinee may have a right to have access to personal information upon request, regardless of whether it is contained in a final report or in the working notes of the evaluator (unless a statutory exception applies). Before disclosing a copy of the IME report, the evaluator should consult with the insurer or third party who requested the IME and/or the CMPA to confirm whether any of the exceptions to disclosure apply. ${ }^{13}$

Independent medical evaluators must maintain their responsibility to do no harm to examinees; however, what legally constitutes harm remains ill-defined. Although the evaluatorexaminee relationship differs from the standard physician-patient relationship, evaluators should consider their responsibility to disclose to the examinee important medical problems uncovered during their assessment. Evaluators may be obligated to provide the IME report and their notes to the examinee upon request. However, this is contingent on the law, the nature of the agreement with the hiring third party and the consent of the examinee. To circumvent misunderstanding and reduce potential conflicts, independent medical evaluators should ensure that examinees understand the purpose of the assessment, what will transpire during the assessment and to whom the report belongs.

\section{References}

1. Baum K. Independent medical examinations: an expanding source of physician liability. Ann Intern Med 2005;142:974-8.

2. Shane JA. Physician-patient relationships may blur during independent medical examinations. Orthopedics Today 2009;29:24.

3. Williams CD. Psychiatric disability assessments. Psychiatr Ann 2006;36:774-83.

4. Branco v. Sunnybrook \& Women's College Health Sciences Centre, OJ No. 3287 (S.C.J.) 2003.

5. Worthman v. AssessMed Inc., 2006 CanLII 7038 (ON SCDC).

6. Grant D. Independent medical examinations and the fuzzy politics of disclosure. CMAJ 1997;156:73-5.

7. Lynch v. Appell, (O.J. No. 4740 (S.C.J) 2001).

8. Independent medical evaluations. Ottawa (ON): The Canadian Medical Protective Association; 2013. Available: https://oplfrpd5 .cmpa-acpm.ca/web/guest/-/independent-medical-evaluations-be -prepared (accessed 2013 Sept. 24).

9. MacDougal S. Getting added value from an independent medical evaluation. OOHNA Journal 2006;Spring:24-7.

10. Brigham CR, Babitsky S. Independent medical evaluations and impairment ratings. Occup Med 1998;13:325-43.

11. Gordon EJ. Independent medical evaluations. Orthop Rev 1985;14: 109-14.

12. Zasler ND. Forensic assessment issues in low level neurological states. Neuropsychol Rehabil 2005;15:251-6.

13. Wyndowe v. Rousseau, 2008 CanLII FCA 39

Affiliations: Department of Clinical Epidemiology and Biostatistics, and Department of Anesthesia (Ebrahim, Busse), McMaster University, Hamilton, Ont.; Stanford Prevention Research Center (Ebrahim), Department of Medicine, Stanford University, Stanford, Calif.; Sava Associates (Sava), Toronto, Ont.; Swiss Academy of Insurance Medicine (Kunz), University Hospital Basel, Basel, Switzerland; Department of Anesthesia and Pain Medicine (Ebrahim), the Hospital for Sick Children, Toronto, Ont.; the Michael G. Degroote Institute for Pain Research and Care (Busse), McMaster University, Hamilton, Ont.

Contributors: Shanil Ebrahim, Regina Kunz and Jason Busse conceived the idea for the manuscript. Shanil Ebrahim drafted the manuscript. Shanil Ebrahim, Helen Sava, Regina Kunz and Jason Busse made substantial contributions and revised several drafts of the paper. All authors approved the final version of the manuscript submitted for publication, and Shanil Ebrahim is guarantor of the work.

Funding: Shanil Ebrahim is supported by a Mitacs Elevate Postdoctoral Fellowship Award and a Sickkids Restracomp Fellowship. Jason Busse is funded by a New Investigator Award from the Canadian Institutes of Health Research and Canadian Chiropractic Research Foundation.

Acknowledgement: The authors thank Dr. Gordon Guyatt for his intellectual input in the study conception and design, and for critically reviewing several drafts of the manuscript. 